cultural projects; and the Beltsville (Md.) Research Center. At the same time, some of the Bureaux were renamed as follows : Bureau of Animal Industry, Office of Experiment Stations, Bureau of Entomology and Plant Quarantine, Bureau of Human Nutrition and Home Economics, Bureau of Dairy Industry, Bureau of Plant Industry, Soils, and Agricultural Engineering, and the Bureau of Agricultural and Industrial Chemistry. The work of the Regional Research Laboratories is now closely integrated with the last.

In addition to these agencies in the Agricultural Research Administration, the Department of Agriculture carries on considerable scientific research in the Forest Service and in the Soil Conservation Service. The Forest Service works in twelve forest and range experiment stations, and the Forest Products Laboratory at Madison, Wis.; the Soil Conservation Service investigates soil erosion and water depletion, and develops methods of soil and water conservation in co-operation with State agricultural experiment stations. Finally, the Bureau of Agricultural Economics is the central statistical and economic research agency of the Department, and has done outstanding work in social and economic science. As a result of Presidential Reorganization Plans announced in 1939 and 1940, the Weather Bureau was transferred to the Department of Commerce, the Food and Drug Administration to the Federal Security Agency, the Bureau of Public Roads to the Federal Works Agency, and the Bureau of Biological Survey to the Department of the Interior, where it became part of the Fish and Wildlife Service.

\section{Summer School in X-Ray Crystallography}

A Summer School in X-ray crystallography for scientific workers in industry, which was first suggested at the second conference on X-rays of the Institute of Physics, was held in Cambridge during September 6-18. It was organized by the Board of Extra-Mural Studies of the University in co-operation with the Cavendish Laboratory and the Department of Mineralogy and Petrology. Only about one third of the applicants could be accommodated; the whole course was attended by twenty-two, and, in addition, a small number were present for one week. The main object of the course was to familiarize $X$-ray workers in industry with the techniques used in solving fundamental problems. Thus they should be better fitted for dealing both with the routine work in industrial organizations and with the special problems that arise from time to time. Accordingly the earlier part of the course was devoted to the study of single-crystal X-ray photographs, and possible and actual practical applications were pointed out. The orientation of diamonds in the making of dies for wire drawing and of artificial sapphires for pivot bearings were two such examples.

The latter part of the course dealt mainly with powders and polycrystalline aggregates, with special reference to metals. The applications of X-ray methods to the study of equilibrium diagrams, of stress and strain, and of preferred orientation in wires and sheets, were described in detail; these were aug* mented by a lecture by Sir Lawrence Bragg on "The Strength of Metals". The identification of materials by the X-ray Index of Powder Photographs was also dealt with. Nineteen lectures were given altogether, by Drs. N. F. M. Henry, H. Lipson and W. A. Wooster: each lecture was followed by two hours of practical work in which assistance was given by
Miss A. M. B. Parker and Dr. D. P. Riley. Since it was not possible for the students actually to use the $\mathrm{X}$-ray apparatus, the practical work was based on photographs or measurements already in existence. Opportunity to see and handle the apparatus was given in special visits to the research laboratories of the Department of Mineralogy and Petrology and the Cavendish Laboratory. The course was noteworthy as an example of fruitful collaboration between industry and a university. At the present time many industrial firms make great use of X-ray diffraction methods, and at the same time, university teachers, in order to train students effectively, need to keep in touch with the practical requirements of industry.

\section{The Cannibal Complex}

Prof. J. H. Hutron's presidential address to the Folk-lore Society deals with the subject of cannibalism (Folk-lore, $54 ; 1943$ ). The thesis is upheld that the origins of the practice were many and various, and that several causes were responsible for the growth of the custom among any given people. Among the reasons for the eating of his own kind by man, Prof. Hutton enumerates the following : famine, lack of meat food in the case of folk living largely on such starchy materials as potatoes and manioc, etc., revenge, and magic. In the last case ideas of sacrifice, of obtaining the life essence or qualities of the person eaten, and of getting an extra 'ddollop' of soul-stuff by the same means can be traced. One is told that 'long pig' makes good eating, but Prof. Hutton does not include this possible motive. It would appear that no one of these reasons by itself is sufficient to generate the custom-indeed the fact that among some cannibals only criminals are eaten suggests that, on the whole, man does not relish eating man. When, however, several of the above factors operate, for example, when famine has started the practice, then it may develop into a custom as a result of the operation of one or more of the other motives. Such an analysis of a 'savage' practice is very interesting and helps to show the ordinary Englishman how complex are the ideas of modern primitive peoples.

\section{The Cuscatlan Bridge in El Salvador}

THIs bridge is the largest in Central America, and has been erected across the Lempa River, to complete another link in the Pan-American Highway (Earthquake Notes, 14, Nos. 3 and 4; June 1943). The main suspension span of $820 \mathrm{ft}$. is carried by cables of open construction chosen to fit the unusual erection conditions. The bridge is near the base of an extinct volcano, and test borings indicated that the foundations and anchorages would be in volcanic materials consisting of cemented ash and loose boulders or stones. These materials lie in very irregular strata and pockets. Since the bridge may be subjected to earthquake shocks, special care was necessary to support the assumed earthquake forces in the design of the concrete approaches. A study of this feature indicated that multiple-span rigidframe structures were required. A factor in the design of structures built to resist earthquakes is the natural period of vibration. Resonance must be avoided by making this different from the supposed destructive earthquake frequencies likely to arise in the district. In this case periods of from 0.5 sec. to 1.5 sec. were avoided. The natural periods of the transverse bents of the Lempa River Bridge concrete 
approaches is less than 0.5 sec. and that of the longitudinal frames is of the order of $0.25 \mathrm{sec}$. A factor contributing to the safety of the longitudinal frames against resonance is the varying heights of the columns, each of which has a natural period of its own different from the others. Tunnel anchorages have been used. The principal mass of the bridge is contained in the main-span trusses and the floor, and this mass would produce the greatest transverse earthquake force on the towers at the level of the trusses. The cables have a small mass but transmit heavy loads to the towers. The earthquake forces on the towers from the cables would be small, and the conservative design of the bridge was not affected by the assumed earthquake forces.

\section{Distribution of Typhus}

According to an editorial in the March issue of the Boletin de la Oficina Sanitaria Panamericana the Panamerican Committee on Typhus and other Rickettsial Diseases set up by the eleventh Panamorican Congress held in Rio de Janeiro in September 1942 has come to the following conclusions. With improvement in the methods of investigation the number of cases and the extent of the geographical areas are becoming more apparent. In Chile and more recently in Bolivia and Columbia there have been several epidemics of typhus. Sporadic cases or small epidemies have been repeatedly notified in the Argentine, Brazil, Peru, Ecuador and Venezuela, while in Central America serious outbreaks have been reported in Guatemala as well as cases in El Salvador, Honduras and most of the Caribbean Islands such as Cuba, Puerto Rico and Jamaica. These diseases form one of the major health problems in some parts of Mexico and the United States, and cases have also been seen in Canada. The rickettsiases found in America may be classified into the following four groups : (1) epidemic, classic, European or louseborne; (2) endemic, murine or flea-borne ; (3) Rocky Mountain spotted fever; and (4) $Q$ fever or nine mile fever, Japanese river fever or tsutsugamushi apparently not found hitherto on the American continent. The problem is particularly serious at the present time owing to the War, the rapid transporta. tion of large numbers of persons to and from infected zones and the difficulty of enforcing maritime and aerial quarantine.

\section{Earthquakes Registered in Spain}

DurING May and Juno 1943, forty-five earthquakes and earth tremors were registered by the five Wiechert seismographs at the Observatory at Toledo, according to provisional bulletins just received. During May there were sixteon shocks, the strongest recording being on May 25, when an earthquake beginning with an unidentified emergent pulse at $23 \mathrm{~h} .22 \mathrm{~m}$. $23 \mathrm{~s}$. attained a maximum amplitude of $480 \mu$ on May 26 at $00 \mathrm{~h} .09 \mathrm{~m} .17 \mathrm{~s}$. An earthquake with an estimated depth of focus of $230 \mathrm{~km}$. began recording with iPze at $17 \mathrm{~h} .29 \mathrm{~m}$. 54s. on May 2. During June there were twenty-nine shocks registered. The greatest registration was on June 13, when an earthquake, beginning with $i P z$ at $5 \mathrm{~h} .24 \mathrm{~m}$. 56s., attained a maximum amplitude of $270 \mu$ at $6 \mathrm{~h}$. $05 \mathrm{~m}$. This shock had a depth of focus of $100 \mathrm{~km}$. The shock of June 20, which was reported as destructive at Adapazar in Turkey, first registerod at $15 \mathrm{~h} .38 \mathrm{~m} .29 \mathrm{~s}$. and attained a maximum amplitude at Toledo of $41 \mu$ at $15 \mathrm{~h} .5 \mathrm{~lm}$. (Nature, July 3, p. 17).

\section{Ciencia}

AN editorial note in tho first issue for 1942 of Ciencia: Revista hispano-americano de Ciencias puras $y$ aplicadas (published in Mexico) expresses the hope that its publication, interrupted for a time, will be regular and punctual in the future. Issues for the first half of 1942 deal with a great variety of subjects, some of cultural interest, others of a practical and technical character, and in addition, it contains short items of scientific importance from a great number of countries. Of special interest is a series of articles (not yet completed) by Prof. B. Cabrera, of the National University of Mexico, entitled "El Atomismo y Su Evolucion", which provide an excellent account of the developments in our knowledge of atomic physics from the days of Democritus and Leucippus up to modern times. Dr. Honorato Castro contributes an article on the determination of the distance between two points on the earth's surface with sufficient accuracy to serve the needs of aviators. A spherical earth is assumed in the first case, and then it is shown how corrections can be applied when an ellipsoidal earth is considered. Biological and medical subjects aro prominent, and among the latter may be noticed an important article by Dr. S. Obrador Alcalde, with the title, "Mecanismos Neurales De Los Ritmos Electricos De La Corteza Cerebral". The author, who is connected with the Laboratory of Medical and Biological Research, School of Medicine and Institute of Neuro-Psychiatry, Mexico, deals with investigations. These few references will suffice to show the scope of the journal, and it may also be mentioned that a considerable amount of space is devoted to reviews of scientific works.

\section{Announcements}

Dr. A. H. Rosenthal, well known as a physicist and clectronic engineer, has been appointed director of research and development of Scophony Corporation of America. Dr. Rosenthal has been connectod with Scophony, Ltd., of London, for several years, and in his present position will head a group of scientific men and engineers engaged in research and development of fundamental inventions, not only in television, but also in the ever-widening field of electronics, including various applications of supersonics.

The inaugural meeting of the X-Ray Analysis Group of the Institute of Physics will be held, by invitation of the Manchester and District Branch of tho Institute, in the Physics Department of the University of Manchester on October 16. Sir Lawrence Bragg will open the meeting with a lecture on "The Physical Optics of X-Ray Analysis", which will be followed by four short papers and an exhibition of $\mathrm{X}$-ray apparatus relating to industrial problems.

The late Sir Horace Boot, the distinguished engineer, has bequeathed $£ 5,000$ to the Institution of Civil Engineers and $£ 1,000$ each to the Institutions of Mechanical and Electrical Engineers.

ReFerence was made in Nature of September 25 (p. 352) to the new American publication, Mathematical Tables and Aids to Computation. We are asked to state that the agent in Great Britain for this periodical is the Scientific Computing Service, Ltd., 23 Bedford Square, London, W.C.1 (subscription $£ \mathrm{l}$ ). 